\section{FRI0184 SAFETY AND EFFICACY OF SPLENECTOMY IN THE TREATMENT OF ANTIPHOSPHOLIPID SYNDROME- ASSOCIATED CYTOPENIAS}

Ana Barrera-Vargas ${ }^{1}$, Juan Rangel Patiño ${ }^{2}$, Samuel Govea-Peláez', Javier Merayo-Chalico ${ }^{1}$, Roberta Demichelis-Gómez ${ }^{2}$, Jorge Alcocer-Varela ${ }^{1}$. ${ }^{1}$ Instituto Nacional de Ciencias Médicas y Nutrición Salvador Zubirán, Immunology and Rheumatology, Mexico City, Mexico; ${ }^{2}$ Instituto Nacional de Ciencias Médicas y Nutrición Salvador Zubirán, Hematology and Oncology, Mexico City, Mexico

Background: Thrombocytopenia and autoimmune hemolytic anemia (AIHA) are common hematologic manifestations in primary antiphospholipid syndrome (APS). Although splenectomy is considered a second-line treatment in both primary immune thrombocytopenia (ITP) and idiopathic AlHA, its role in APS patients with either one of these manifestations has not been adequately defined, mainly because of the theoretically increased risk of thrombosis for patients with APS who undergo surgery.

Objectives: To determine the safety and efficacy of splenectomy for steroid-refractory thrombocytopenia or autoimmune hemolytic anemia in patients with primary APS, when compared to patients with ITP or idiopathic AlHA.

Methods: We performed a retrospective, single-center, case-control study. We included patients with primary APS and either thrombocytopenia, or autoimmune hemolytic anemia/Evans syndrome who underwent splenectomy between 2000 and 2018. The control group was made up by patients with primary immune cytopenias (ITP or AIHA) who also underwent splenectomy during that period. Cases and controls were adjusted by age, the hematologic manifestation and date of splenectomy. We recorded demographic, clinical and serologic characteristics at the time of surgery and during follow-up.

Results: We included 34 patients in each group. Thrombocytopenia was the indication for splenectomy in $53 \%$ of patients, with AlHA or Evans syndrome comprising the remaining $47 \%$. Most patients were female $(78 \%)$ and median age was 37 years. Among APS patients, $41 \%$ had triple antibody positivity.

There were no differences regarding comorbidities between groups. Patients with APS received more immunosuppressive treatment lines before splenectomy compared to controls $(p=0.02)$, and there was a trend for more high-dose steroid cycles in the APS group $(p=0.07)$. Median time to splenectomy was 54 months in APS patients and 18 months in controls, but without statistical significance.

Regarding splenectomy, most were laparoscopic (88\%) and surgical complications were similar between groups (18\%). However, patients with APS had a higher incidence of global non-surgical complications in the first month ( 50 vs $23 \%, p=0.04$ ), most of them being infections (21 vs $3 \%, p=0.05)$. There was no difference in the incidence of postsurgical thrombosis, venous or arterial, between groups.

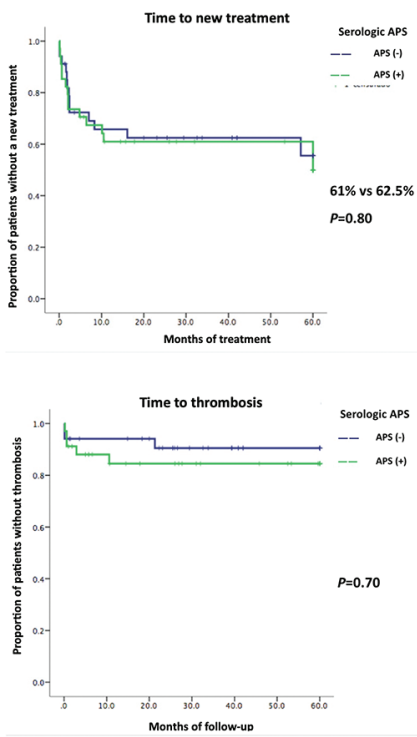

Most patients achieved a global response after one month $(85 \%$ in APS group, $91 \%$ in controls, $p=0.7)$. Complete response was observed in $65 \%$ and $79 \%$ of cases and controls, respectively $(p=0.27)$. Median follow-up time was 52 months for APS patients and 41 months for controls. There were no differences regarding relapse which required any treatment adjustment between cases and controls $(44 \%$ and $38 \%$, respectively, $\mathrm{p}=0.8$, Fig 1). However, $47 \%$ of APS patients received a prolonged maintenance immunosuppressive treatment, compared with $6 \%$ of controls $(p<0.01)$. The incidence of infections and thrombosis during follow-up was similar between groups ( $p=0.15$ and $p=0.7$, respectively; Fig 2).

Conclusion: Splenectomy is associated with adequate and long-lasting responses in APS patients with cytopenias, which do not differ from patients with non-APS-associated thrombocytopenia and AlHA. Thrombosis was not a common complication in our patients; however, there was a higher incidence of infections in APS patients. This could be related to the higher steroid doses and more intensive previous immunosuppressive therapies. Splenectomy could be considered an earlier treatment option for APS patients with refractory cytopenias, and this could reduce infection risk and post-surgical morbidity.

Disclosure of Interests: Ana Barrera-Vargas: None declared, Juan Rangel Patiño: None declared, Samuel Govea-Peláez: None declared, Javier Merayo-Chalico Speakers bureau: Pfizer, Roberta Demichelis-Gómez: None declared, Jorge Alcocer-Varela: None declared

DOI: 10.1136/annrheumdis-2019-eular.7610

\section{FRI0185 HYDROXYCHLOROQUINE FOR THE PREVENTION OF RELAPSES IN A SERIES OF 812 PATIENTS WITH PRIMARY ANTIPHOSPHOLIPID SYNDROME: THE HIBISCUS RETROSPECTIVE STUDY}

Cristina Belizna $^{1,2}$, Ljudmila Stojanovich ${ }^{3}$, Patrick Saulnier ${ }^{1}$,

Francesca Pregnolato ${ }^{4}$, Jaume Alijotas-Reig ${ }^{5}$, Enrique Esteve-Valverde ${ }^{6}$,

Omar Latino ${ }^{7}$, Sebastien Udry ${ }^{8}$, Natasa Stanisavljevic ${ }^{9}$, Alexander Makatsariya ${ }^{10}$, Jamilya Khizroeva ${ }^{10}$, Maarten Limper ${ }^{11}$, Angela Tincani ${ }^{12}$, Laura Andreoli ${ }^{12}$, Francesca Regola ${ }^{12}$, Cecilia Chighizola ${ }^{4}$, Maria Orietta Borghi ${ }^{13}$, Sule

Apras Bilgen ${ }^{14}$, Levent Kılıç ${ }^{14}$, Arsene Mekinian ${ }^{15}$, Valentina Canti ${ }^{16}$,

Katrien Devreese ${ }^{17}$, Gilberto Pires Rosa ${ }^{18}$, Laura Damian ${ }^{19}$, Fatma Said ${ }^{20}$, Yehuda Shoenfeld ${ }^{21}$, Ricard Cervera ${ }^{22}$, Pier Luigi Meroni ${ }^{23}$, 'Zahir Amoura ${ }^{24}$ HIBISCUS consortium. ' ${ }^{1}$ University Hospital Angers, Angers, France; ${ }^{2}$ CNRS 6015 INSERM 1083, Angers, France; ${ }^{3}$ Scientific Research Department, Internal Medicine-Rheumatology Bezhanijska Kosa, University Medical Center, Belgrade, Serbia; ${ }^{4}$ Istituto Auxologico Italiano, Milan, Italy, ${ }^{5}$ Vall d'Hebron University Hospital, Barcelona, Spain, BArcelona, Spain; ${ }^{6}$ Althaia Healthcare Network of Manresa, Barcelona, Spain; ${ }^{7}$ Hospital Carlos G. Durand, Buenos Aires, Argentina; ${ }^{8} \mathrm{Hospital}$ Carlos G. Durand, Buenos Aires, Buenos Aires, Argentina; ${ }^{9}$ Bezhanijska Kosa, University Medical Center, Belgrade University, Serbia, Belgrade, Serbia; ${ }^{10}$ I.M. Sechenow First Moscow State Medical University, Moscow, Moscow, Russian Federation; ${ }^{11}$ UMC UTRECHT, UTRECHT, Netherlands; ${ }^{12}$ Rheumatology and Clinical Immunology Unit, University of Brescia, Brescia, Italy, Brescia, Italy;

${ }^{13}$ University of Milan, Milan, Italy; ${ }^{14}$ Hacettepe University, Ankara, Ankara, Turkey; ${ }^{15}$ APHP Saint Antoine, PAris, France; ${ }^{16}$ Hospital San Raffaele, Milan, Italy; ${ }^{17}$ Ghent University Hospital, Ghent, Belgium, Ghent, Belgium; ${ }^{18}$ Sao Joao Hospital, Porto, Alameda, Porto, Portugal; ${ }^{19}$ Emergency Clinical County, Cluj, Romania; ${ }^{20}$ University Hospital La Rabta, TUNIS, Tunis, Tunisia; ${ }^{21}$ The Zabludowicz Center for Autoimmune Diseases, affiliated to Sackler Faculty of Medicine, Tel-Aviv University, Israel, Tel Aviv, Israel; ${ }^{22}$ University of Barcelona, Barcelona, Spain; ${ }^{23}$ Istituto Auxologico Italiano, Milan, Italy, ${ }^{24}$ APHP, PAris, France

Background: The relapse rate in antiphospholipid syndrome (APS) remains high, $20 \%$ at 5 years in thrombotic APS and $28 \%$ in obstetrical APS (1). Hydroxychloroquine (HCQ) appears as an additional therapy, with immunomodulatory and antithrombotic effects (2-5).

Objectives: The main aim of this trial is to assess the efficacy of treatment with Hydroxychloroquine in preventing new events in primary antiphospholipid syndrome patients.

Methods: We have performed a retrospective multicentre open-labelled study (2002-2018).

Results: 812 patients with APS from 53 international centres from 16 countries were included. In all cases, the previous standard treatment was inefficient. The mean follow-up was 20.2 months (8- $144 \mathrm{mo}$ ), the mean age 39.5 years old. The type of clinical manifestations is described in figure 1. 


\begin{tabular}{|l|l|l|}
\hline Obstetrical & Thrombotic & Both \\
\hline 377 & 320 & 115 \\
\hline $46,3 \%$ & $39,7 \%$ & $14 \%$ \\
\hline
\end{tabular}

Miscarriages $40 \%$

Fœtal loss 31\%

Preeclampsia $12 \%$ IUGR $11 \%$

Multiple type of obstetrical events $10 \%$

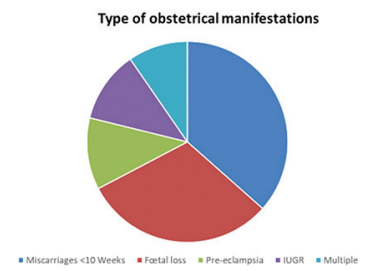

Recurrence with $\mathrm{HCQ}$



The obstetrical manifestations were various as described in figure 2 .

The number of thrombotic events were 190 arterial and 187 venous. Triple antiphospholipid antibody (tAPL) positivity was found in $20 \%$ of patients and lupus anticoagulant (LA) in $22 \%$. No bleeding was registered in $99,6 \%$ of cases with treatment by HCQ. HCQ use was associated with favourable outcome in $96 \%$ of cases (figure 3).

In multivariate analysis, age more than 65 years was associated with arterial events (odds-ratio $0.1395 \% \mathrm{Cl} 0.03-0.32$, p 0.005).

Conclusion: HCQ could be effective in cases of refractory APS but prospective studies are necessary.

\section{REFERENCES:}

[1] Cervera R, Serrano R, Pons-Estel GJ, Ceberio-Hualde L, Shoenfeld Y, de Ramón E, Buonaiuto V, Jacobsen S, Zeher MM, Tarr T, Tincani A, Taglietti M, Theodossiades G, Nomikou E, Galeazzi M, Bellisai F, Meroni PL, Derksen RH, de Groot PG, Baleva M, Mosca M, Bombardieri S, Houssiau F, Gris JC, Quéré I, Hachulla E, Vasconcelos C, Fernández-Nebro A, Haro M, Amoura Z, Miyara M, Tektonidou M, Espinosa G, Bertolaccini ML, Khamashta MA. Morbidity and mortality in the antiphospholipid syndrome during a 10-year period: a multicentre prospective study of 1000 patients. Ann Rheum Dis. 2015;74:1011-8.

[2] Belizna C. Hydroxychloroquine as an anti-thrombotic in antiphospholipid syndrome. Autoimmun Rev. 2015;14:358-62.

[3] Nuri E, Taraborelli M, Andreoli L, Tonello M, Gerosa M, Calligaro A, Argolini LM, Kumar R, Pengo V, Meroni PL, Ruffatti A, Tincani A. Long-term use of hydroxychloroquine reduces antiphospholipid antibodies levels in patients with primary antiphospholipid syndrome. Immunol Res. 2017;65:17-24
[4] Schmidt-Tanguy A, Voswinkel J, Henrion D, Subra JF, Loufrani L, Rohmer $V$, et al. Antithrombotic effects of hydroxychloroquine in primary antiphospholipid syndrome patients. J Thromb Haemost JTH. 2013;11:1927-9.

Disclosure of Interests: Cristina Belizna: None declared, Ljudmila Stojanovich: None declared, Patrick Saulnier: None declared, Francesca Pregnolato: None declared, Jaume Alijotas-Reig: None declared, Enrique EsteveValverde: None declared, Omar Latino: None declared, Sebastien Udry: None declared, Natasa Stanisavljevic: None declared, Alexander Makatsariya: None declared, Jamilya Khizroeva: None declared, Maarten Limper Consultant for: GSK, Roche and Thermofisher, Speakers bureau: GSK and Roche, Angela Tincani Consultant for: UCB, Pfizer, Abbvie, BMS, Sanofi, Roche, GSK, AlphaSigma, Lilly, Jannsen, Cellgene, Novartis, Laura Andreoli: None declared, Francesca Regola: None declared, Cecilia Chighizola Speakers bureau: Inova Diagnostics, Maria Orietta Borghi: None declared, Sule Apras Bilgen: None declared, Levent Kilıç: None declared, Arsene Mekinian: None declared, Valentina Canti: None declared, Katrien Devreese: None declared, Gilberto Pires Rosa: None declared, Laura Damian: None declared, Fatma Said: None declared, Yehuda Shoenfeld: None declared, Ricard Cervera: None declared, Pier Luigi Meroni Consultant for: Inova, Thermofisher, Teofarma, Zahir Amoura: None declared

DOI: 10.1136/annrheumdis-2019-eular.7838

\section{FRI0186 HYDROXYCHLOROQUINE ON THE TOP OF STANDARD TREATMENT WITH LOW DOSE ASPIRIN AND LOW MOLECULAR WEIGHT HEPARIN SIGNIFICANTLY REDUCES THE PROBABILITY OF PREGNANCY MORBIDITY IN WOMEN WITH MULTIPLE POSITIVITY FOR ANTI-PHOSPHOLIPID ANTIBODIES}

Cecilia Chighizola ${ }^{1}$, Francesca Pregnolato ${ }^{1}$, Francesca Bartoli ${ }^{2,3}$, Maria Gerosa ${ }^{2,3}$, Chiara Comerio $0^{2,4}$, Maria Gabriella Raimondi ${ }^{2,3}$, Laura Trespidi ${ }^{4}$, Maria Orietta Borghi ${ }^{1,2}$, Manuela Wally Ossola ${ }^{4}$, Enrico Ferrazzi ${ }^{2,4}$, Pier Luigi Meroni ${ }^{1}$ ${ }^{1}$ Istituto Auxologico Italiano, Milan, Italy; ${ }^{2}$ University of Milan, Department of Clinical Sciences and Community Health, Milan, Italy; ${ }^{3}$ ASST Gaetano Pini, Rheumatology, Milan, Italy; ${ }^{4}$ Fondazione Cà Granda, Ospedale Maggiore Policlinico, Department of Obstetrics and Gynaecology, Milan, Italy

Background: Hydroxychloroquine is an anti-malarial drug that not only exerts immunomodulatory and anti-thrombotic properties, but also has been shown to reverse several effects mediated by anti-phospholipid antibodies (aPL) in models of obstetric anti-phospholipid syndrome (APS). Not surprisingly, $H C Q$, whose prescription during gestation is perfectly safe, has been proposed as an additional therapeutic tool in obstetric APS, but evidence of ist efficacy is still scant.

Objectives: This study investigates how treatment with $\mathrm{HCQ}$, prescribed in different combinations with low-dose aspirin (LDASA) and low-molecular weight heparin (LMWH), affects the probability of pregnancy morbidity $\left(\mathrm{P}_{\mathrm{PM}}\right)$.

Methods: Data on pregnancies in women with persistent aPL positivity at any titre, with or without autoimmune diseases, were retrospectively collected at a single centre.

A weigthed generalized estimated equation (GEE) model was applied to quantify the effect of treatment with $\mathrm{HCQ}$ on $\mathrm{P}_{\mathrm{PM}}$, allowing to: i) evaluate pregnancy outcomes over time using available Iongitudinal data; ii) account that pregnancies of the same woman are not independent events; iii) consider that women had a different number of pregnancies; iv) estimate the role of several confounders and predictors.

The model envisaged as dependent variable pregnancy outcome as a binary outcome, defined for each pregnancy as "obstetric complication yes versus no" (pregnancy loss before 10 weeks, pregnancy loss after 10 weeks, premature birth before 34 weeks, according to updated APS classification criteria).

Results: Three-hundred-eighty-one women were recruited in this study: 155 women with aPL positivity (100 women with positivity for criteria aPL and 55 women with low titer $\mathrm{aPL}$ ) and 226 women with autoimmune diseases but negative aPL. Data were collected on 847 pregnancies: 458 in women with positive aPL (172 in women with criteria $\mathrm{aPL}$ and 286 in women with low titer aPL) and 389 in women with autoimmune disease and negative aPL.

$P_{\mathrm{PM}}$ in untreated patients are presented in Table 1. Table 2 reports $\mathrm{P}_{\mathrm{PM}}$ in women receiving LDASA+/- HCQ, LDASA + LMWH +/- HCQ.

Conclusion: HCQ, when added to LDASA or on the top of standard treatment with LDASA and LMWH, allows to reduce $\mathrm{P}_{\mathrm{PM}}$. Most importantly, HCQ plus the combo LMWH + LDASA leads to a significantly 